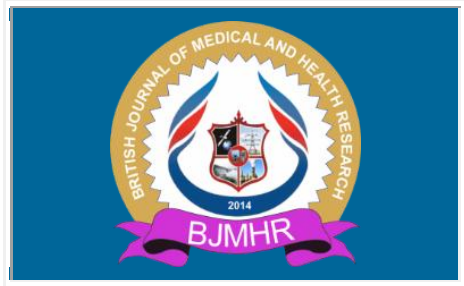

\title{
BJMHR
}

British Journal of Medical and Health Research Journal home page: www.bjmhr.com

\section{Knowledge and Practices of Omani Adolescent Girls Related to Menstruation}

\section{*Sanam Anwar, Juhaina Ahmed Said Al Jahwari, Mazoun Nasser Rashid Al Kharousi, Asma Hamed Ahmed Al Adawi, Ruqaiya Abdul Samad, Noor Al-Zubaidi MD Community Medicine, Head of the Department, Epidemiology \& Public Health, Oman Medical College, Sohar}

\section{ABSTRACT}

An adolescent girl should be made aware of the phenomenon of menstruation before menarche, so as to enable her to accept it as a normal developmental process and manage it appropriately. Less attention has been given to the effect that menarche itself and the management of monthly menstrual periods may have on school attendance, learning outcomes, and continued school enrollment. This study was done with the objectives of assessing the knowledge and practices of adolescent girls related to menstruation. It was carried out in school going adolescent girls. A pretested structured questionnaire was used to collect information on knowledge and practices of girls related to menstruation after taking informed consent. Majority of girls $(78.8 \%)$ had knowledge about menstruation before attaining menarche. Main source of knowledge about menstruation was girls' family $(60.2 \%)$. Majority of girls (56\%) felt that the duration of menses ranged between 7-8 days. Majority (95.8\%) knew that menses occur once a month. Only 56\% knew the right duration of normal menstrual cycles. During menstruation $(31.2 \%)$ one third of the students skipped school. Almost $34 \%$ took medication for pain during menstruation without any prescription. It was found that $32.6 \%$ girls used heating pads and $35.1 \%$ girls used herbal remedies to get relief from dysmenorrhea. Most of the girls had knowledge on menstruation from their families. During menstruation one third of the students skipped school and took medication for menstrual pain without prescription. Herbal remedies were used by one third of girls to relieve this pain.

Keywords: Menstruation, knowledge, practice, school, adolescent 


\section{INTRODUCTION}

Adolescent girls constitute a vulnerable group not only with respect to their social status but also in relation to their health. More than half of the world's population is below the age of 25 , and one in every two young people in the world is adolescent $\left[^{1}\right]$.

Menstruation is a normal physiology in females. Menarche is the most important event in the life of an adolescent girl $\left[{ }^{2}\right]$. Menstruation, the periodic vaginal bleeding that occurs with the shedding of the uterine mucosa is one of the signs of puberty, and occurs one or two years following appearance of secondary sexual characteristics $\left[{ }^{3}\right]$. Once established, every mature female menstruates on the average 3-5 days (minimum 2 days, maximum 7 days) each month until menopause $\left[{ }^{4}\right]$. An adolescent girl should be made aware of the phenomenon of menstruation before menarche, so as to enable her to accept it as a normal developmental process and manage it appropriately [ $\left.{ }^{5}\right]$. Remaining stable during menstruation requires that females especially the adolescents are prepared psychologically to develop the associated power and mastery over the physiological changes that occur during this period. They should have sufficient knowledge surrounding menstruation, menstrual cycle and of menstrual hygiene even before they attain menarche. Collective knowledge of age at menarche, menstrual cycle and duration of menstrual flow in adolescents is also useful for allaying fears and psychological trauma that may arise from an unexpected appearance of blood per vagina at menarche $\left[{ }^{6}\right]$.

Many studies have revealed that most of the adolescent girls had incomplete and inaccurate information about the menstrual physiology and hygiene. It also revealed that mothers, television, friends, teachers and relatives were the main sources which provided information on menstruation to the adolescent girls $\left[{ }^{7,8}\right]$.

Less attention has been given to the effect that menarche itself and the management of monthly menstrual periods may have on school attendance, learning outcomes, and continued school enrollment. Menstruation creates a set of physical, socio-cultural and economic challenges that may interfere with a young woman's ability to attend school or to participate fully in classroom activity. The management of menstruation 1 has recently emerged as a domain for interventions designed to maintain adolescent girls' school attendance with the ultimate goal of reducing dropout rates and supporting adolescent girls through secondary school $\left[{ }^{9}\right]$. Furthermore, a new body of literature addresses the impact of menstrual management on adolescent girls and their identity development during the transition to adulthood $\left[{ }^{10}\right]$.

Thus the current study was done with the objective to assess the knowledge, perception and practice of adolescent girls related to menstruation. It was envisaged that findings from the 
study will be a pointer to some adolescence reproductive health needs in Oman, and will also provide foundation for policy makers to make rational decision on improving adolescence reproductive health in Oman.

\section{MATERIALS AND METHODS}

A community based cross-sectional study design was used to collect data from adolescent school going girls in Omani high schools of Sohar wilayat in Oman. With the ministry of health support, permission was obtained from all the girls-only government schools in Sohar for data collection. Girls studying in grade 9 or 10 at the time survey formed the sampling unit for this study. A total of 359 girls across 8 high schools in Oman were included in the study after taking informed consent from them. The data collection tool for this study was a self-administered pretested questionnaire which was structured with definite items. The questionnaire was validated after piloting it in few girls in one of the schools. After the pilot study, the questions with ambiguity or unclear answers were modified. The research proposal was approved by the Ministry of Health.

The questionnaire included questions regarding socio-demographic variables, knowledge and practices related to menstruation. All participants received a gift in the form of a diary which included health education material regarding nutritional advice, healthy practices during menstruation and a calendar to keep track of their menstrual cycles.

Statistical Package for the Social Sciences Software was used to analyze the data. Data was summarized as number of girls and percent for each item assessed in the questionnaire. Descriptive statistical analysis included proportion, percentages for categorical data and mean and standard deviation for continuous data types was used.

\section{RESULTS AND DISCUSSION}

The study was done in Wilayat of Sohar among 359 school going Omani girls. The participants were female students enrolled in grade $9(40.7 \%)$ and grade $10(59.3 \%)$. The mean age of the girls was 15.11 years \pm 0.799 S.D. The age of participants ranged from $14-$ 17 years. Out of the eight girls school in Sohar Wilayat, the largest group of students was from Um Salem school (32\%) followed by Al Shifa (13.9\%) and Tareef School (12\%). Majority of the girls' mothers were educated (60.9\%) while $39 \%$ were illiterate (Table 1$)$.

Table 1: Sociodemographic profile of the participants

\begin{tabular}{lll}
\hline $\begin{array}{l}\text { Variables } \\
\text { Age (years) }\end{array}$ & No. \& (\%) of girls \\
\hline & 13 & $1(0.3)$ \\
14 & $84(23.4)$ \\
15 & $159(44.3)$ \\
& 16 & $103(28.7)$ \\
17 & $11(3.0)$ \\
\hline
\end{tabular}




\begin{tabular}{lll}
\hline Grade of school & 19 & $1(0.3)$ \\
& 9 & $146(40.7)$ \\
Mother's education & 10 & $213(59.3)$ \\
& Illiterate & $140(39.1)$ \\
& High-school & $157(43.7)$ \\
& Graduate & $22(6.1)$ \\
& Post-graduate & $40(11.1)$ \\
Name of school & & \\
& Um Salem & $115(32)$ \\
& Al Shifa & $50(13.9)$ \\
& Tareef & $43(12)$ \\
& Al Fateh & $39(10.9)$ \\
& Al Safa & $33(9.2)$ \\
& Ume Mara & $33(9.2)$ \\
& Tabook & $27(7.5)$ \\
& Balqees & $19(5.3)$ \\
\hline
\end{tabular}

Questions related to knowledge on normal menstruation cycle were asked. Majority of girls (78.8\%) had knowledge about menstruation before attaining menarche. The source of knowledge about menstruation for 476 girls $(60.2 \%)$ was mostly their family whereas 287 girls $(36.3 \%)$ got information from their schools. Only 28 girls (3.5\%) reported friends as their source as depicted in Figure 1.

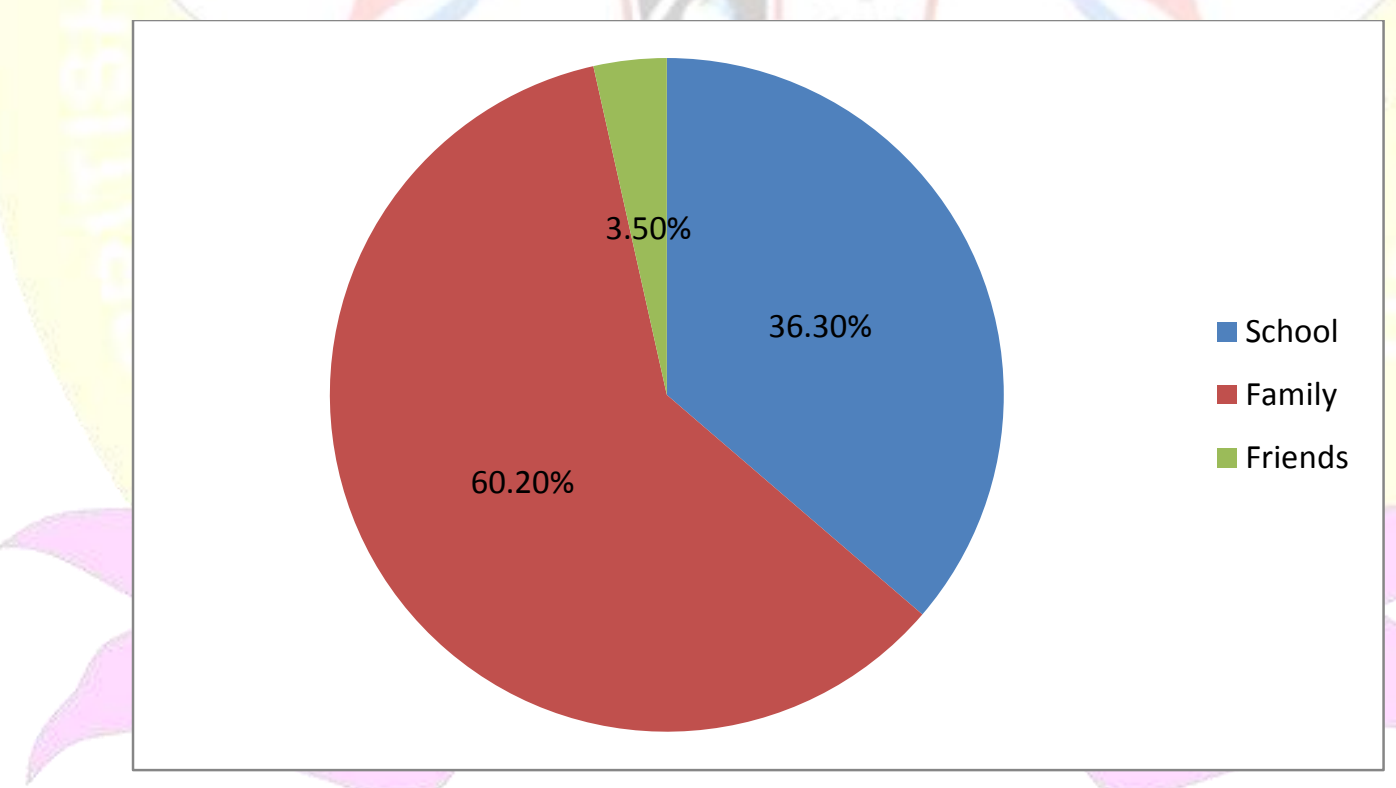

Figure 1: Source of knowledge of menstruation

Media did not play any role in this aspect. When asked about the duration of normal menstrual cycles, majority of girls (56\%) felt that it ranged between $7-8$ days; $35.6 \%$ felt that the duration is 5-6 days; only $2.3 \%$ thought that menses last for 9-10 days. The vast majority of girls knew that menses occur once a month (95.8\%); very few students thought that the frequency of menstruation was twice a month $(2.8 \%)$. When asked at what grade a girl 
usually gets her first menses, most of them felt that it occurs in grade 6 to 8 (86.9\%). Only $6 \%$ of the students felt that it occurs in grade 9-10 (Table 2).

Table 2: Knowledge of girls about menstruation

\begin{tabular}{|c|c|c|}
\hline Knowledge attributes & & No. \& (\%) of girls \\
\hline \multicolumn{3}{|c|}{ Duration of menstruation (days) } \\
\hline & $3-4$ & $22(6.1)$ \\
\hline & $5-6$ & $128(35.6)$ \\
\hline & $7-8$ & $201(56)$ \\
\hline & $9-10$ & $8(2.3)$ \\
\hline \multicolumn{3}{|c|}{ Frequency of menstruation } \\
\hline & Once a month & $344(95.8)$ \\
\hline & Two times a month & $10(2.8)$ \\
\hline & Once in two months & $5(1.4)$ \\
\hline \multicolumn{3}{|c|}{ Grade of school in which menstruation occurs } \\
\hline & $\leq 5$ & $25(7)$ \\
\hline & & $\begin{array}{l}82(22.8) \\
151(42.1)\end{array}$ \\
\hline & 8 & $79(22)$ \\
\hline \multicolumn{3}{|c|}{ Time when knowledge of menstruation was gained } \\
\hline & Before attaining menarche & $283(78.8)$ \\
\hline & After attaining menarche & $76(21.2)$ \\
\hline
\end{tabular}

Questions on practices of adolescent girls during menstruation were elicited. During menstruation one third of the students skipped school (31.2\%) and 62.7\% girls limited their physical activity. A small percentage of them (12.5\%) visited the hospital. Almost $66 \%$ do not take any treatment while one third of the students (34\%) took medication for pain during menstruation without any prescription; of these $88.8 \%$ get pain relief with medications. The use of non-pharmacological ways of pain relief was also assessed. It was found that $32.6 \%$ girls used heating pads and $35.1 \%$ girls used herbal remedies to get relief from dysmenorrhea (Table 3).

Table 3: Practices during menstruation

\begin{tabular}{lll}
\hline Practice attributes & No. \& $(\%)$ of girls \\
\hline \multicolumn{1}{l}{ Visit hospital during menstruation } & \\
& Every time & $8(2.2)$ \\
& Sometime & $37(10.3)$ \\
Never & $314(87.5)$ \\
Take over the counter medications & \\
& Every time & $35(9.7)$ \\
& Sometime & $87(24.3)$ \\
& Never & $237(66)$ \\
Use herbal remedies & & \\
& Every time & $36(10)$ \\
& Sometime & $90(25.1)$ \\
& Never & $233(64.9)$ \\
Use heating pad to relieve pain & \\
\hline
\end{tabular}




\begin{tabular}{cc}
\hline Every time & $45(12.5)$ \\
Sometime & $72(20.1)$ \\
Never & $242(67.4)$ \\
Limit physical activity during menstruation \\
Every time & $87(24.3)$ \\
Sometime & $138(38.4)$ \\
Never & $134(37.3)$ \\
\hline
\end{tabular}

Majority of the girls $(78.8 \%)$ had knowledge about menstruation before attaining menarche. A similar percentage of girls $(79.3 \%)$ were reported in Western Ethiopia [ $\left.{ }^{11}\right]$. While in the study from Nepal, 67.2\% knew about menstruation before menarche [ $\left.{ }^{12}\right]$. The source of knowledge was mostly their family $(60.2 \%)$ whereas $36.3 \%$ got the knowledge from their schools in the current study. Only a few girls, reported friends as the source of information. Media did not play any role in this aspect. Similar finding was observed in the Indian study in Tumkur where $52.11 \%$ of girls, were aware about menstruation before menarche, and were mostly informed by their mother $\left[{ }^{2}\right]$. While study from Ethiopia had contrasting results wherein $67.8 \%$ girls got information from friends, $57 \%$ from media and 35\% from mothers $\left[{ }^{11}\right]$. While in Bangladesh, $44 \%$ girls knew about menstruation from television $\left[{ }^{13}\right]$. These differences highlight the cultural differences across the globe.

Almost half of the girls (56\%) had adequate information on normal menstrual cycles. Similar $(51.3 \%)$ figures were reported from Ethiopian study $\left[{ }^{11}\right]$, while study from Nigeria and Nepal reported lower figures of $4 \%$ and $40.6 \%$ respectively [ ${ }^{14,15}$ ]. In the current study, $95.8 \%$ girls knew that menstruation occurs once a month normally and almost 56\% knew the menstruation duration of normal cycles. Lawan et al reported similar findings where $97 \%$ girls knew correct frequency of menstruation and similar percentage of 58.8\% girls knew the duration of normal menses $\left[{ }^{16}\right]$.

Almost $66 \%$ girls did not take any treatment in the current study which is similar to the findings by Shoor et al $\left[{ }^{1}\right]$ who reported that $52.8 \%$ girls did not take any treatment. The use of over the counter medications in the study was about $34 \%$ while Al-Kindi et al in Oman, reported a lower percentage of only $21 \%\left[{ }^{17}\right]$. A higher percentage $(54 \%)$ of girls using over the counter medications was found in the study done by Sadiq et al $\left[{ }^{18}\right]$.About $12.5 \%$ girls visit the hospital because of pain during menstruation in the current study, this being more than the number of girls consulting a physician due to dysmenorrhea (3\%) reported in AlKindi's study $\left[{ }^{17}\right]$.Sharma et al noted that only $4 \%$ girls went to doctor for treatment $\left[{ }^{3}\right]$. The use of heating pads was $32.6 \%$ and herbal remedies was $35.1 \%$ during menstruation which was far more than what was reported by Al-Kindi as $12 \%$ for heating pads and $12 \%$ for herbal remedies $\left[{ }^{17}\right]$. Shoor et al found $18.7 \%$ girls using home remedies for relief of pain $\left[{ }^{1}\right]$. These findings reiterate the fact that the health seeking behavior of girls is differential based 
on the convenience of services; culture has a strong influence especially on the use of herbal remedies during menstruation.

One third of the girls (31.2\%) reported skipping school during menstruation. Al-Kindi et al in Oman $\left[{ }^{17}\right]$ reported absenteeism of about $45 \%$ while a lower percentage $(23.6 \%)$ was reported by Sadiq et al in Baghdad. $\left[{ }^{18}\right]$ Two thirds of the girls (62.6\%) reported that they restrict their physical activity while menstruating compared to a higher percentage $(84.2 \%)$ reported by Sadiq et al. $\left[{ }^{18}\right]$ While only $25.3 \%$ girls restricted physical activities in the Haryana study done in India $\left[{ }^{19}\right]$.

\section{CONCLUSION}

The participants of this study were found to have fair knowledge about menstruation. Main source of information related to menstruation was their families. The most common practices during menses were absenteeism from schools, the use of over the counter medications, and use of herbal remedies such as cinnamon. The study recommends that the adolescent girls should be sensitized for health seeking behavior of dysmenorrhea as it causes a lot of absenteeism in schools and affects the scholarly activities. The clinic in schools should have conducive environment to give services to the girls so that they can rest, get sanitary pads and medicine appropriately without missing the whole day. As families were the first informant to majority of the adolescent girls, the health education activities can be extended to the mothers regarding safe practices, over the counter medication and health seeking behavior of girls. This study highlighted the need of adolescent girls to have accurate and adequate information about menstruation and its appropriate management with healthy menstrual practices. Mothers should be armed with the correct and appropriate information on reproductive health, so that they can give this knowledge to her growing girl child. It is also essential for the teachers, to impart reproductive health education including menstrual hygiene to the students.

\section{ACKNWLEDGEMENT}

The authors are thankful to the school authorities and nurses who helped in data collection. The authors are also thankful to the Ministry of Health for its support.

\section{REFERENCES}

1. Shoor P. A study of knowledge, attitude, and practices of menstrual health among adolescent school girls in urban field practice area of medical college, Tumkur. Indian J Health Sci Biomed Res 2017;10:249-55. 
2. Lawan UM, Nafisa Wali Yusuf, Aisha Bala Musa. Menstruation and Menstrual Hygiene amongst Adolescent School Girls in Kano, Northwestern Nigeria. African Journal of Reproductive Health Sept 2010; 14(3): 201-7.

3. Sharma P, Malhotra C, Taneja DK, Saha R. Problems related to menstruation amongst adolescent girls. Indian J Pediatr 2008; 75:125-9.

4. WHO/UNFPA/UNICEF. Programming for Adolescent Health and Development. Report of a WHO / UNFPA /UNICEF Study Group on Programming for Adolescent Health. Technical Report Series. Geneva. 1999 No.886.

5. Khadilkar VV, Stanhope RG, Khadilkar V. Secular trends in puberty. Indian Paediat 2006; 43:475-8.

6. Oyebola DO. Female Reproduction. Essential Physiology for Students of Medicine, Pharmacy and Related Disciplines. Nihort Press, Ibadan 2002: 232- 244.

7. Sommer Marni. An Early Window of Opportunity for Promoting Girls' Health: Policy Implications of the Girl's Puberty Book Project in Tanzania. International Electronic Journal of Health Education. 2011; 14:77-92.

8. Bachloo T, Kumar R, Goyal A, Singh P, Yadav SS, Bhardwaj A, Mittal A. A study on perception and practice of menstruation among school going adolescent girls in district Ambala Haryana, India. Int J Community Med Public Health 2016; 3:931- 7.

9. Nagar S, Aimol KR. Knowledge of Adolescent Girls Regarding Menstruation in Tribal Areas of Meghalaya 2010; 8(1):27-30.

10. Sapkota D, Sharma D, Budhathoki SS , Khanal VK, Pokharel HP. Knowledge and practices regarding menstruation among school going adolescents of rural Nepal. Journal of Kathmandu Medical College 2013; 2(3):122-128.

11. Shivaleela P. Upashe, Tesfalidet Tekelab, Jalane Mekonnen. Assessment of knowledge and practice of menstrual hygiene among high school girls in Western Ethiopia. BMC Women's Health 201515:84. https://doi.org/10.1186/s12905-0150245-7

12. Nadira Parvin, Bonita Parvin, Md Monoarul Haque, Mohammad Shahinoor Islam. Knowledge on Menstruation Among Adolescent School Girls in A Selected Area of Dhaka City. Chattagram Maa-O-Shishu Hospital Medical College Journal 2016; 15(1): $31-34$.

13. William F and Ganong MD. The Female Reproductive System. Review of Medical Physiology. Lange 21st Ed. 2003: 437-451.

14. Khadilkar VV, Stanhope RG, Khadilkar V. Secular trends in puberty. Indian Paediat 2006; 43:475-8. 
15. Tegegne T, Sisay M. Menstrual hygiene management and school absenteeism among female adolescent students in Northeast Ethiopia. BMC Public Health 2014; 14(1118). doi:10.1186/1471-2458-14-1118.

16. Oyebola DO. Female Reproduction. Essential Physiology for Students of Medicine, Pharmacy and Related Disciplines. Nihort Press, Ibadan 2002: 232- 244.

17. Al-Kindi, Al-Bulushi A. Prevalence and impact of dysmenorrhoea among Omani high school students. Sultan Qaboos Univ Med J 2011;11(4):485-91.

18. Sadiq MA, Salih AA. Knowledge and practice of adolescent females about menstruation in Baghdad. J Gen Pract 2013; 2:138. doi: 10.4172/2329-9126.1000138.

19. Abioye-Kuteyi Menstrual knowledge and practices amongst secondary school girls in Ile-Ife, Nigeria. The Journal of the Royal Society for the Promotion of Health 2000; 120:23-26.

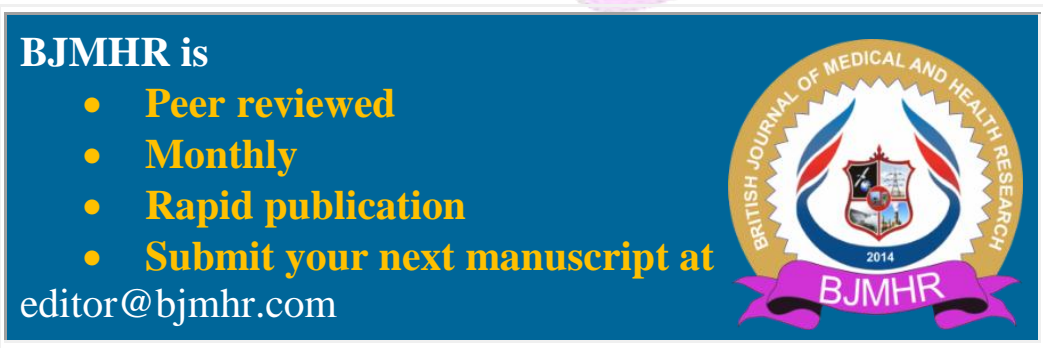

